\title{
Randomised controlled trial of Alexander technique lessons, exercise, and massage (ATEAM) for chronic and recurrent back pain: economic evaluation
}

\author{
Sandra Hollinghurst, senior lecturer in health economics, ${ }^{1}$ Debbie Sharp, professor of primary health care, ${ }^{1}$ \\ Kathleen Ballard, Alexander technique teacher, ${ }^{3}$ Jane Barnett, research nurse, ${ }^{2}$ Angela Beattie, trial \\ manager, ${ }^{1}$ Maggie Evans, trial manager, ${ }^{1}$ George Lewith, reader, ${ }^{2}$ Karen Middleton, data manager, ${ }^{2}$ \\ Frances Oxford, Alexander technique teacher, ${ }^{3}$ Fran Webley, trial coordinator, ${ }^{2}$ Paul Little, professor of \\ primary care research ${ }^{2}$
}

${ }^{1}$ Academic Unit of Primary Health Care, University of Bristol, Bristol BS8 2AA

${ }^{2}$ Primary Care Group, CCS Division, University of Southampton, Aldermoor Health Centre, Southampton S016 5ST

${ }^{3}$ Society of Teachers of the Alexander Technique, Linton House, London NW5 1RS Correspondence to: S Hollinghurst s.p.hollinghurst@bristol.ac.uk

Cite this as: BMJ 2008;337:a2656 doi:10.1136/bmj.a2656

\section{ABSTRACT}

Objective An economic evaluation of therapeutic massage, exercise, and lessons in the Alexander technique for treating persistent back pain.

Design Cost consequences study and cost effectiveness analysis at 12 month follow-up of a factorial randomised controlled trial.

Participants 579 patients with chronic or recurrent low back pain recruited from primary care.

Interventions Normal care (control), massage, and six or 24 lessons in the Alexander technique. Half of each group were randomised to a prescription for exercise from a doctor plus behavioural counselling from a nurse.

Main outcome measures Costs to the NHS and to participants. Comparison of costs with Roland-Morris disability score (number of activities impaired by pain), days in pain, and quality adjusted life years (QALYs). Comparison of NHS costs with QALY gain, using incremental cost effectiveness ratios and cost effectiveness acceptability curves.

Results Intervention costs ranged from $£ 30$ for exercise prescription to $£ 596$ for 24 lessons in Alexander technique plus exercise. Cost of health services ranged from $£ 50$ for 24 lessons in Alexander technique to $£ 124$ for exercise. Incremental cost effectiveness analysis of single therapies showed that exercise offered best value ( $£ 61$ per point on disability score, $£ 9$ per additional pain-free day, $£ 2847$ per QALY gain). For two-stage therapy, six lessons in Alexander technique combined with exercise was the best value (additional $£ 64$ per point on disability score, £43 per additional pain-free day, £5332 per QALY gain).

Conclusions An exercise prescription and six lessons in Alexander technique alone were both more than $85 \%$ likely to be cost effective at values above $£ 20000$ per QALY, but the Alexander technique performed better than exercise on the full range of outcomes. A combination of six lessons in Alexander technique lessons followed by exercise was the most effective and cost effective option.

\section{INTRODUCTION}

Back pain is one of the most common reasons for patients to consult in primary care and is costly for both health services and society. ${ }^{1}$ Previous studies of the effectiveness of lessons in the Alexander technique and massage for patients with chronic back pain have focused on clinical outcomes. We have found no reports of an economic evaluation of either of these interventions. The cost implications of prescribed exercise have been evaluated in two studies. Moffett et al concluded that a community exercise programme resulted in lower use of healthcare services in the intervention group but that this cost saving was not sufficient to offset the intervention cost. ${ }^{2}$ No estimate of cost effectiveness was reported. In the UKBEAM trial a class based exercise programme with and without spinal manipulation was evaluated: the combined treatment offered good value, but exercise alone was less cost effective as it cost more and produced fewer quality adjusted life years (QALYs). ${ }^{3}$ Acupuncture has been shown to reduce pain and be relatively cost effective ( $£ 4241$ per QALY gained) over two years. ${ }^{4}$

In this study we compare the costs and outcomes at 12 months of courses of six and 24 lessons in the Alexander technique, six sessions of massage, and a general practitioner's prescription for home based exercise with a nurse follow-up for patients with chronic or recurrent non-specific back pain in primary care.

\section{METHODS}

The main study design and interventions are described in detail in our associated paper. ${ }^{5}$ Briefly, we conducted a randomised controlled trial using a $4 \times 2$ factorial design, in which participants from 64 general practices were randomised to one of eight groups. A short course of six lessons in the Alexander technique, a longer course of 24 lessons, and six sessions of massage were compared with normal care- half with and half without a doctor's prescription for home based general 
exercise and a practice nurse's behavioural counselling.

We carried out the economic evaluation 12 months after randomisation of participants, conducting it from the perspectives of the NHS, participants, and society. We included costs to the NHS, personal costs to participants, and time off work and unpaid activities. NHS costs included the intervention, primary care contacts, outpatient appointments, inpatient hospital stays, and medication. Personal costs included travel associated with back pain treatment, any private treatment and over the counter preparations, prescription charges, loss of earnings, and expenditure on domestic help and care giving. Societal costs included the value of time off work or unpaid activities and the value of informal care.

We analysed the data in two ways. Individual group analysis was used to provide the most relevant information for policy makers, and we carried out marginal analysis in line with the convention for a factorial design. ${ }^{6}$ In both cases we compared each intervention group with the most appropriate comparator group as shown in table 1 .

We estimated cost to the NHS and patients separately, and conducted a cost effectiveness analysis

\begin{tabular}{|c|c|}
\hline $\begin{array}{l}\text { Table } 1 \mid \text { Interventions for chron } \\
579 \text { patients recruited from pr } \\
\text { between the trial groups }\end{array}$ & $\begin{array}{l}\text { ic or recurrent low back pain in } \\
\text { imary care and comparisons }\end{array}$ \\
\hline Intervention groups & Comparator groups \\
\hline Individual group analysis & \\
\hline Massage alone & Normal care \\
\hline $\begin{array}{l}\text { Six lessons in Alexander technique } \\
\text { alone }\end{array}$ & Normal care \\
\hline $\begin{array}{l}24 \text { lessons in Alexander technique } \\
\text { alone }\end{array}$ & $\begin{array}{l}\text { Six lessons in Alexander technique } \\
\text { alone }\end{array}$ \\
\hline Normal care plus exercise & Normal care \\
\hline & Massage alone \\
\hline Thassage plus exercise & Normal care plus exercise \\
\hline Six lessons in Alexander technique & $\begin{array}{l}\text { Six lessons in Alexander technique } \\
\text { alone }\end{array}$ \\
\hline pius exercise & Normal care plus exercise \\
\hline 24 lessons in Alexander technique & $\begin{array}{l}24 \text { lessons in Alexander technique } \\
\text { alone }\end{array}$ \\
\hline plus exercise & $\begin{array}{l}\text { Six lessons in Alexander technique } \\
\text { plus exercise }\end{array}$ \\
\hline Factorial group analysis & \\
\hline $\begin{array}{l}\text { Massage (with and without } \\
\text { exercise) }\end{array}$ & $\begin{array}{l}\text { Normal care with and without } \\
\text { exercise }\end{array}$ \\
\hline $\begin{array}{l}\text { Six lessons in Alexander technique } \\
\text { (with and without exercise) }\end{array}$ & $\begin{array}{l}\text { Normal care with and without } \\
\text { exercise }\end{array}$ \\
\hline $\begin{array}{l}24 \text { lessons in Alexander technique } \\
\text { (with and without exercise) }\end{array}$ & $\begin{array}{l}\text { Six lessons in Alexander technique } \\
\text { with and without exercise }\end{array}$ \\
\hline $\begin{array}{l}\text { Exercise (with and without } \\
\text { massage or Alexander technique ( } 6 \\
\text { or } 24 \text { lessons)) }\end{array}$ & $\begin{array}{l}\text { Normal care, massage, and } \\
\text { Alexander technique ( } 6 \text { or } 24 \\
\text { lessons) without exercise }\end{array}$ \\
\hline $\begin{array}{l}\text { Massage=Six sessions of therapeuti } \\
\text { Lessons in Alexander technique=Eit } \\
\text { weeks and one a week for two week } \\
\text { weeks, one a week for six weeks, or } \\
\text { revision lessons at seven months ar } \\
\text { Exercise=General practitioner's exer } \\
\text { sessions of behavioural counselling }\end{array}$ & $\begin{array}{l}\text { c massage, one session per week. } \\
\text { her six lessons (two a week for two } \\
\text { s) or } 24 \text { lessons (two a week for six } \\
\text { ne fortnightly for eight weeks, and } \\
\text { nd nine months). } \\
\text { cise prescription, and up to three } \\
\text { with practice nurse. }\end{array}$ \\
\hline
\end{tabular}

that compared cost to the NHS with the primary outcome of the Roland-Morris disability questionnaire, ${ }^{7}$ the number of days in pain, ${ }^{8}$ and the QALY gain estimated from the European quality of life instrument EQ-5D. ${ }^{9}$ We estimated cost effectiveness acceptability curves for the individual treatment groups to indicate the level of uncertainty around the point estimates of cost per QALY.

\section{Data collection}

Table 2 shows the data sources and unit costs used in this study. We collected resource use data prospectively during the trial. We recorded the number of intervention sessions attended, extracted details of primary care visits and prescribed drugs for back pain from practice records, and took other information from participants' self completed questionnaires conducted at three-monthly intervals. The EQ-5D was conducted at baseline, three months, and 12 months.

We used unit costs in pounds sterling at 2005 prices. We based primary care costs on Curtis and Netten, ${ }^{10}$ secondary care costs on the Department of Health national tariff, ${ }^{11}$ and drug costs on the British National Formulary. ${ }^{12}$ The exercise prescription, which included both general practitioner and practice nurse time, was costed as primary care consultations, and the Alexander technique and massage interventions were costed at the rate paid to teachers and therapists during the trial. A charge was made for a missed appointment but not after a patient dropped out of the trial. Personal costs were self reported except for travel by car, for which we used the AA schedule of motoring costs. ${ }^{13}$ No adjustment for inflation was necessary.

\section{Data analysis}

Data extracted from primary care records were available for all participants. Some questionnaire data, including the EQ-5D responses, were missing because of some participants dropping out or failing to answer all the questions. Complete personal cost data were available for $62 \%$ of patients, and the overall proportion of missing data points was 35\%. We had complete EQ-5D data for 306 (53\%) patients: the data were complete for $92 \%$ of participants at baseline, $72 \%$ at three months, and $62 \%$ at 12 months, giving a total of $25 \%$ missing data points. The level of completeness declined to $68 \%$ for the period from baseline to three months and to $55 \%$ for the time from three months to 12 months, giving an overall level of $62 \%$.

We filled in the missing data points by means of imputation by chained equation using STATA, release 9. ${ }^{15}$ This method imputes missing values using an iterative multivariable regression technique. Any number of variables can be used in the regression, and any number of complete imputations may be created. In this study we used all available EQ-5D data, plus the intervention group variable; we used 20 cycles of five imputations.

The EQ-5D data were used to estimate QALY gain per patient over the 12 month period using the published social tariff for EQ-5D. ${ }^{16}$ We used the 
"area under the curve approach," adjusted for baseline differences across the groups, to calculate QALY gain. ${ }^{17}$

Uncertainty in assumptions or estimates made during the analysis were addressed in a series of oneway sensitivity analyses. We estimated uncertainty around the incremental cost effectiveness ratios of cost per QALY using the bootstrapping technique. We generated 1000 replications of each incremental cost effectiveness ratio and used them to derive cost effectiveness acceptability curves.

It was not necessary to discount the costs and outcomes, as the time horizon of the study was one year. All analyses were carried out using Microsoft Excel and STATA $9 .{ }^{15}$

\section{RESULTS}

A total of 579 participants were randomised across the eight groups. Table 3 shows their resource use relating to back pain. Four hundred and seventeen (72\%) patients had no primary care contacts relating to back pain during the course of the study, 98 (17\%) had one, and 64 patients $(11 \%)$ had two or more. Seventy five

Table 2 | Data sources and unit costs used in costing interventions for chronic or recurrent low back pain

Unit cost $(£)$

Primary care:

\begin{tabular}{ll} 
Doctor practice consultation & $24.00^{\star}$ \\
\hline Doctor telephone consultation & $25.00^{\star}$ \\
\hline Doctor home visit & $69.00^{\star}$ \\
\hline Practice nurse consultation & $10.00^{\star}$ \\
\hline Nurse practitioner consultation & $15.00^{\star}$ \\
\hline "Out of hours" doctor telephone consultation & $54.95 \dagger$ \\
\hline "Out of hours" doctor home visit & $69.00^{\star}$ \\
\hline Primary care physiotherapist & $20.00^{\star}$ \\
\hline Visit to accident and emergency department & $61.00 \ddagger$
\end{tabular}

Outpatient appointments:

Orthopaedics or musculoskeletal

133.00 (first visit), 67.00 (follow-up) $\ddagger$

Rheumatology

Pain management, health psychology, neurology 196.00(first visit), 91.00 (follow-up)‡

Physiotherapy 185.00 (first visit), 85.00 (follow-up) $\ddagger$

Homoeopathic hospital $90.32 \ddagger$

Inpatient stays:

Posterior lumbar interbody fusion (HRG R16, 13 nights)

$71.20 \S$

Pain management ward (HRG A07, 21 nights)

Neurology (pain relief) (HRG A07, 14 nights)

Prescribed drugs

Travel by car

Intervention:

Alexander technique, massage

Exercise prescription (doctor consultation)

Exercise prescription (nurse consultation)

$2065 \ddagger$

$2984 \ddagger$

$2172 \ddagger$

By individual drugf

0.50 per mile**

*From Curtis et al. ${ }^{10}$

†Practice consultation grossed up by Beale et al. ${ }^{14}$

fFrom Department of Health tariff. ${ }^{11}$

$\S$ Reported directly

TFrom British National Formulary. ${ }^{12}$

${ }^{\star *}$ From the AA schedule. ${ }^{13}$

††Rate paid to therapists and teachers taking part in the study.
$(13 \%)$ patients had at least one outpatient visit; most referrals were to physiotherapy, orthopaedics, and pain management. There were three inpatient stays: two for pain management and one for back surgery. Prescribed drug use was higher in the control than in the intervention groups. One hundred and sixty three (28\%) participants received at least one prescription for drugs associated with back pain during the year (such as analgesics, muscle relaxants, non-steroidal anti-inflammatory drugs, and antidepressants). The mean number of items per patient for prescribed drugs was $2.7(95 \%$ confidence interval 2.4 to 3.0).

Thirty per cent of participants had time off work during the year because of back pain, and $62 \%$ were prevented from carrying out unpaid activities. The overall mean length of time off work was just under a week and the maximum about six months. On average, participants received half an hour of informal care each week, but only $50 \%$ of participants completed this section of the questionnaire. These resource items were neither valued nor included in the incremental analysis as there is no evidence of a difference across the groups and inclusion of lost productivity as a cost in cost effectiveness ratios is controversial. ${ }^{18}$

Table 4 shows the mean cost per patient by intervention group. Providing the intervention accounted for $77 \%$ of the NHS costs. The cost of other health services was greatest for the patients prescribed normal care plus exercise $(£ 124)$ and those receiving massage alone (£98). Mean out of pocket expenses were $£ 319$ per patient, with $£ 135(42 \%)$ of this relating to expenditure on private therapies.

\section{Cost effectiveness analysis}

Table 5 shows the incremental mean cost per patient to the NHS compared with the change in the Roland disability score, days free of pain, and QALYs. The incremental cost effectiveness ratios indicate the cost to the NHS of a gain in health as measured by each outcome. Of the three "single" interventions (massage, six lessons in Alexander technique, and exercise), exercise is best value on all three outcomes. Adding an extra therapy provides greater benefit at extra cost in all cases, with six lessons in the Alexander technique plus exercise looking to be best value. Table 6 gives the incremental cost effectiveness ratios for the "factorial" groups. Exercise (with and without other therapies) has the lowest ratio for the disability score and QALYs as it is cheapest and delivers the second highest gain, but it scores poorly on pain-free days. Patients receiving six lessons in the Alexander technique (with and without the exercise intervention) perform well on all outcomes.

The figure shows the cost effectiveness acceptability curves based on individual group QALY. These illustrate the scale of uncertainty around the point estimates of cost per QALY given in table 5 and indicate the optimal choice of intervention for a given threshold price. Exercise has the highest probability of being the most cost effective first choice of therapy. If exercise is the first choice, policy makers would have to 
Table $3 \mid$ Use of resources related to interventions for persistent low back pain in 579 patients. Values are mean (SD) numbers of resource items unless stated otherwise

\begin{tabular}{|c|c|c|c|c|c|c|c|c|}
\hline & \multicolumn{8}{|c|}{ Intervention } \\
\hline & \multicolumn{4}{|c|}{ Without exercise } & \multicolumn{4}{|c|}{ With exercise } \\
\hline & Normal care & Massage & $\begin{array}{c}\text { Alexander technique } \\
\text { (6 lessons) }\end{array}$ & $\begin{array}{l}\text { Alexander technique } \\
\text { (24 lessons) }\end{array}$ & Normal care & Massage & $\begin{array}{l}\text { Alexander technique } \\
\text { (6 lessons) }\end{array}$ & $\begin{array}{l}\text { Alexander technique } \\
\text { (24 lessons) }\end{array}$ \\
\hline \multicolumn{9}{|l|}{ NHS resource use } \\
\hline Primary care contacts & $0.43(0.71)$ & $0.67(1.33)$ & $0.48(0.94)$ & $0.44(0.91)$ & $0.50(0.99)$ & $0.32(0.75)$ & $0.35(0.83)$ & $0.59(1.02)$ \\
\hline $\begin{array}{l}\text { Outpatient } \\
\text { appointments }\end{array}$ & $0.32(0.89)$ & $0.27(0.70)$ & $0.27(0.73)$ & $0.15(0.64)$ & $0.14(0.48)$ & $0.19(0.60)$ & $0.21(0.65)$ & $0.25(0.89)$ \\
\hline Inpatient nights & $0(0)$ & $0(0)$ & $0(0)$ & $0(0)$ & $0.47(2.89)$ & $0.19(1.65)$ & $0(0)$ & $0(0)$ \\
\hline Prescriptions & $0.85(1.64)$ & $0.77(1.65)$ & $0.64(1.17)$ & $1.07(2.24)$ & $0.88(1.56)$ & $0.60(1.55)$ & $0.58(1.26)$ & $0.68(1.75)$ \\
\hline $\begin{array}{l}\text { Sessions of Alexander } \\
\text { technique or massage }\end{array}$ & N/A & $5.23(1.72)$ & $5.23(1.81)$ & $18.58(8.71)$ & $\mathrm{N} / \mathrm{A}$ & $5.18(1.81)$ & $5.44(1.54)$ & $18.76(8.42)$ \\
\hline Exercise sessions & $\mathrm{N} / \mathrm{A}$ & $\mathrm{N} / \mathrm{A}$ & $\mathrm{N} / \mathrm{A}$ & $\mathrm{N} / \mathrm{A}$ & $2.21(1.42)$ & $2.53(1.53)$ & $2.77(1.39)$ & $2.51(1.71)$ \\
\hline \multicolumn{9}{|l|}{ Societal resource use } \\
\hline $\begin{array}{l}\text { No }(\%) \text { of patients } \\
\text { having some time off } \\
\text { work }(n=496)\end{array}$ & $16(27.1)$ & $25(35.2)$ & $21(32.8)$ & $24(36.9)$ & $12(21.8)$ & $16(25.0)$ & $18(29.5)$ & $18(31.6)$ \\
\hline $\begin{array}{l}\text { No }(\%) \text { of patients } \\
\text { having time off other } \\
\text { activities }(n=496)\end{array}$ & $41(69.5)$ & $53(74.6)$ & $40(62.5)$ & $33(50.8)$ & $34(61.8)$ & $41(64.1)$ & $35(57.4)$ & $31(54.4)$ \\
\hline Days off work $(n=295)$ & $6.59(18.7)$ & $10.40(25.4)$ & $5.32(17.8)$ & $1.85(4.3)$ & $1.02(2.7)$ & $3.25(7.2)$ & $1.97(6.7)$ & $4.58(19.3)$ \\
\hline $\begin{array}{l}\text { Hours informal care } \\
(n=285)\end{array}$ & $27.50(54.6)$ & $45.75(75.0)$ & $20.58(47.8)$ & $4.44(8.3)$ & $17.79(43.7)$ & $28.49(78.1)$ & $30.06(73.5)$ & $44.28(170.7)$ \\
\hline
\end{tabular}

be prepared to pay more than $£ 18000$ per QALY gain to be $80 \%$ sure that a second intervention is cost effective. If exercise is disregarded as first choice because it performs poorly on pain-free days and, to some extent, on the Roland disability score, six lessons in the Alexander technique becomes the most attractive first option. The addition of exercise provides a worthwhile benefit at a modest cost and is more than $80 \%$ likely to be cost effective at values above $£ 5000$ per QALY.
Sensitivity analysis

The sensitivity analysis (table 7) addresses three areas of uncertainty. As the cost of the intervention was the major NHS expense, we looked at the effect of adherence. Although it is unlikely that adherence would ever be complete in practice, this provides a benchmark for assessing generalisability. If all patients had attended all intervention sessions, the overall mean cost per patient would have been $18 \%$ higher. The greatest discrepancy is with the two groups assigned to

Table $4 \mid$ Costs of resources used in relation to interventions for persistent low back pain in 579 patients. Values are mean (SD) costs ( $£$ )

\begin{tabular}{|c|c|c|c|c|c|c|c|c|}
\hline & \multicolumn{8}{|c|}{ Intervention } \\
\hline & \multicolumn{4}{|c|}{ Without exercise } & \multicolumn{4}{|c|}{ With exercise } \\
\hline & Normal care & Massage & $\begin{array}{l}\text { Alexander } \\
\text { technique } \\
\text { (6 lessons) }\end{array}$ & $\begin{array}{c}\text { Alexander } \\
\text { technique } \\
\text { (24 lessons) }\end{array}$ & Normal care & Massage & $\begin{array}{l}\text { Alexander } \\
\text { technique } \\
\text { (6 lessons) }\end{array}$ & $\begin{array}{c}\text { Alexander } \\
\text { technique } \\
\text { (24 lessons) }\end{array}$ \\
\hline \multicolumn{9}{|l|}{ NHS costs } \\
\hline Intervention & $\mathrm{N} / \mathrm{A}$ & $160.40(50.4)$ & $158.63(52.8)$ & $560.14(258.4)$ & $29.89(15.8)$ & $188.56(60.2)$ & $198.07(55.4)$ & $596.28(260.0)$ \\
\hline GP visits & 11.03 (18.04) & 34.51 (84.96) & $13.40(27.03)$ & $17.71(46.68)$ & $20.96(64.72)$ & $14.42(35.94)$ & $14.75(43.31)$ & $16.94(35.41)$ \\
\hline Other primary care & $0.35(2.11)$ & $0.00(0.00)$ & $0.14(1.17)$ & $0.97(7.22)$ & $0.00(0.00)$ & $0.00(0.00)$ & $0.28(2.37)$ & $0.00(0.00)$ \\
\hline Secondary care & $33.26(86.85)$ & $49.27(135.7)$ & $38.08(103.2)$ & $21.75(95.27)$ & 90.39 (462.9) & $56.07(324.7)$ & $21.99(62.44)$ & $40.71(142.1)$ \\
\hline Medication & $9.82(27.85)$ & $13.99(56.50)$ & $7.62(31.28)$ & $9.60(26.57)$ & 13.09 (45.49) & $8.21(32.90)$ & $4.82(13.69)$ & $7.25(26.25)$ \\
\hline Total & $54.46(100.4)$ & $258.16(204.4)$ & $217.86(145.9)$ & $610.17(262.3)$ & $154.33(523.2)$ & $267.25(363.4)$ & $239.92(106.9)$ & $661.18(328.3)$ \\
\hline \multicolumn{9}{|c|}{ Personal costs ( $35 \%$ imputed) } \\
\hline Travel & $12.20(26.81)$ & $72.58(310.8)$ & $16.19(23.80)$ & $78.97(123.1)$ & $14.26(31.52)$ & $48.72(126.45$ & $18.35(21.05$ & 69.97 (89.98) \\
\hline Private therapy & $169.65(226.4)$ & $210.72(820.5)$ & $101.79(271.2)$ & $89.90(166.6)$ & $57.22(134.5)$ & $175.99(286.9)$ & $113.06(258.0)$ & $157.67(361.3)$ \\
\hline Prescription charges & $8.84(30.15)$ & $20.91(48.13)$ & $9.26(25.98)$ & $2.78(9.62)$ & $12.43(31.2)$ & $8.15(23.74)$ & $2.55(6.60)$ & $8.88(31.14)$ \\
\hline $\begin{array}{l}\text { Over the counter } \\
\text { drugs }\end{array}$ & $18.74(34.58)$ & $10.05(21.78)$ & $9.88(18.41)$ & $8.42(18.48)$ & $9.45(22.29)$ & $7.10(12.80)$ & $9.07(16.44)$ & $10.51(25.79)$ \\
\hline Loss of earnings & $67.01(260.8)$ & $84.01(430.4)$ & $90.55(638.4)$ & $30.10(133.8)$ & $16.36(93.78)$ & $62.43(363.8)$ & $49.94(327.8)$ & $92.86(415.5)$ \\
\hline $\begin{array}{l}\text { Paid domestic help } \\
\text { and care giving }\end{array}$ & $98.32(274.1)$ & $29.40(217.8)$ & $46.30(147.1)$ & $71.34(273.0)$ & $77.44(246.7)$ & $54.61(280.8)$ & $5.56(32.34)$ & $107.15(650.8)$ \\
\hline Total & $374.77(503.1)$ & $427.67(1221)$ & $273.97(932.1)$ & $281.50(449.5)$ & $187.16(361.2)$ & $357.01(641.2)$ & $198.54(421.8)$ & $447.03(1102)$ \\
\hline
\end{tabular}


Table $5 \mid$ Incremental costs, benefits, and cost effectiveness of interventions for persistent low back pain compared with most appropriate comparator group. Values are incremental means $(95 \% \mathrm{Cl})$ unless stated otherwise

\begin{tabular}{|c|c|c|c|c|c|c|c|c|}
\hline & \multicolumn{3}{|c|}{ Single intervention } & \multicolumn{4}{|c|}{ Double or two stage intervention } & \multirow{2}{*}{$\begin{array}{c}\text { Three stage } \\
\text { intervention }\end{array}$} \\
\hline & Massage* & $\begin{array}{l}\text { Alexander } \\
\text { technique (6 } \\
\text { lessons)* }\end{array}$ & Exercise* & $\begin{array}{l}\text { Alexander } \\
\text { technique ( } 24 \\
\text { lessons) } \dagger\end{array}$ & $\begin{array}{l}\text { Massage plus } \\
\text { exercise } \neq\end{array}$ & $\begin{array}{l}\text { Alexander } \\
\text { technique }(6 \\
\text { lessons) plus } \\
\text { exercise } \neq\end{array}$ & $\begin{array}{l}\text { Alexander } \\
\text { technique }(6 \\
\text { lessons) plus } \\
\text { exercise } †\end{array}$ & \\
\hline Cost to the NHS $(£)(n=579)$ & 204 (151 to 257) & 163 (122 to 205) & 100 (-24 to 224$)$ & 392 (323 to 462) & $113(-25$ to 261$)$ & $86(-40$ to 211$)$ & $22(-20$ to 64$)$ & 421 (340 to 502$)$ \\
\hline $\begin{array}{l}\text { Roland disability score } \\
(\mathrm{n}=462)\end{array}$ & $\begin{array}{c}-0.45(-2.30 \text { to } \\
1.39)\end{array}$ & $\begin{array}{c}1.44(-3.34 \text { to } \\
0.45)\end{array}$ & $\begin{array}{c}-1.65(-3.62 \text { to } \\
0.31)\end{array}$ & $\begin{array}{c}-2.70(-4.60 \text { to } \\
-0.82)\end{array}$ & $\begin{array}{c}-0.72(-2.66 \text { to } \\
1.22)\end{array}$ & $\begin{array}{c}-1.33(-3.27 \text { to } \\
0.61)\end{array}$ & $\begin{array}{c}-1.54(-3.44 \text { to } \\
0.36)\end{array}$ & $\begin{array}{c}-1.24(-3.15 \text { to } \\
0.67)\end{array}$ \\
\hline $\begin{array}{l}\text { Days free of back pain in past } \\
\text { four weeks }(n=435)\end{array}$ & $8(-4$ to 19$)$ & 13 (1 to 25$)$ & 11 (1 to 23$)$ & $7(-5$ to 19$)$ & $0(-11$ to 11$)$ & $2(-10$ to 14$)$ & $0(-12$ to 12$)$ & $7(-5$ to 19$)$ \\
\hline $\begin{array}{l}\text { QALY gain }(n=579 ; 38 \% \\
\text { imputed) }\end{array}$ & $\begin{array}{c}-0.01(-0.05 \text { to } \\
0.04)\end{array}$ & $\begin{array}{c}0.03(-0.01 \text { to } \\
0.06)\end{array}$ & $\begin{array}{c}0.04(0.00 \text { to } \\
0.07)\end{array}$ & $\begin{array}{c}0.02(-0.02 \text { to } \\
0.06)\end{array}$ & $\begin{array}{c}0.02(-0.02 \text { to } \\
0.06)\end{array}$ & $\begin{array}{c}0.02(-0.03 \text { to } \\
0.06)\end{array}$ & $\begin{array}{c}0.02(-0.02 \text { to } \\
0.07)\end{array}$ & $\begin{array}{c}0.03(-0.01 \text { to } \\
0.07)\end{array}$ \\
\hline $\begin{array}{l}\text { Incremental cost to NHS of a } \\
\text { point reduction in disability } \\
\text { score }(£)\end{array}$ & 448 & 113 & 61 & 145 & 157 & 64 & 14 & 340 \\
\hline $\begin{array}{l}\text { Incremental cost to NHS per } \\
\text { pain-free day during past four } \\
\text { weeks }(£)\end{array}$ & 26 & 13 & 9 & 56 & - & 43 & - & 60 \\
\hline $\begin{array}{l}\text { Incremental cost } \\
\text { effectiveness ratio: NHS cost } \\
\text { per QALY gain }(£)\end{array}$ & -34473 & 5899 & 2847 & 20993 & 5304 & 5332 & 915 & 13914 \\
\hline
\end{tabular}

*Compared with normal care alone.

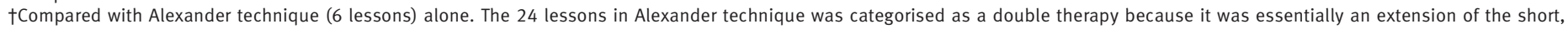
6 week course.

$\ddagger$ Compared with normal care plus exercise.

$\S$ Compared with Alexander technique (6 lessons) plus exercise.

24 lessons in the Alexander technique, where NHS costs would have been $26 \%$ higher.

Secondly, we looked at the effect of inpatient stays, which are relatively expensive. Excluding these reduces overall costs by $4 \%$ with the greatest reduction $(45 \%)$ in the group assigned to exercise alone, which contained two of the three patients concerned.

Finally, we looked at the effect of imputing data relating to personal costs and QALY gain that were missing from the questionnaire responses. The estimated mean personal costs were $3 \%$ lower when we used only the complete cases $(n=358)$ rather than the full (imputed) dataset. This difference varies across the groups, with the largest difference in the group prescribed normal care plus exercise, who had the poorest record for returning the completed questionnaire $(46 \%)$. The estimates of QALY gain using only the complete cases increases the variation across the groups, with the normal care plus exercise group showing the greatest difference.

\section{DISCUSSION}

Principal findings

Care for patients receiving one of the seven combinations of interventions to treat back pain cost the NHS between $£ 100$ (for normal care plus exercise) and $£ 607$ (for 24 lessons in the Alexander technique plus exercise) over the 12 months after entry to the study. Benefits provided were additional pain-free days (8-20 per patient, by group, over four weeks), an improvement in ability to perform daily activities (reduction in the Roland disability score of 0.45-4.22 per patient, by group), and a gain in QALYs of up to 0.065 per patient, by group (except the group allocated massage alone,

Table 6 | Incremental costs, benefits, and cost effectiveness for "factorial" groups of interventions for persistent low back pain compared with most appropriate comparator groups. Values are incremental means $(95 \% \mathrm{Cl})$ unless stated otherwise

\begin{tabular}{|c|c|c|c|c|}
\hline & Massage* $^{*}$ & Alexander technique (6 lessons)* & Alexander technique (24 lessons) $\dagger$ & Exercise \\
\hline Cost to the NHS $(£)(n=579)$ & 158.22 (80.39 to 236.05$)$ & $124.34(59.04$ to 189.65$)$ & 406.58 (353.56 to 459.60$)$ & $44.07(-13.04$ to 101.17$)$ \\
\hline Roland disability score $(n=462)$ & $-0.58(-1.95$ to 0.77$)$ & $-1.40(-2.77$ to -0.03$)$ & $-2.00(-3.37$ to -0.64$)$ & $-1.29(-2.25$ to -0.34$)$ \\
\hline Days free of back pain in past four weeks $(n=435)$ & 7 (3 to 12$)$ & $10(5$ to 15$)$ & 8 (3 to 13$)$ & $2(1$ to 5$)$ \\
\hline QALY gain ( $n=579 ; 38 \%$ imputed) & $0.015(-0.010$ to 0.040$)$ & $0.022(-0.005$ to 0.049$)$ & $0.023(-0.006$ to 0.053$)$ & $0.040(0.020$ to 0.060$)$ \\
\hline $\begin{array}{l}\text { Incremental cost effectiveness ratio: NHS cost per } \\
\text { point reduction in disability score }(£)\end{array}$ & 272.79 & 88.81 & 203.29 & 34.16 \\
\hline $\begin{array}{l}\text { Incremental cost effectiveness ratio: NHS cost per } \\
\text { pain-free day during past four weeks }(£)\end{array}$ & 22.30 & 12.43 & 50.82 & 22.04 \\
\hline $\begin{array}{l}\text { Incremental cost effectiveness ratio: NHS cost per } \\
\text { QALY gain }(£)\end{array}$ & 10793 & 5704 & 17454 & 1096 \\
\hline
\end{tabular}

*Compared with normal care with and without exercise.

†Compared with Alexander technique (6 lessons) with and without exercise.

$\ddagger$ Compared with normal care, massage, and Alexander technique (6 or 24 lessons) without exercise. 
First choice intervention

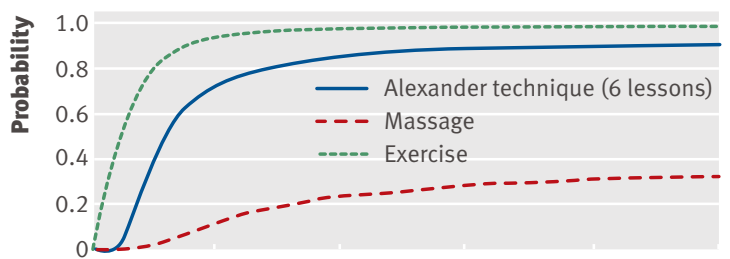

Second intervention when Alexander technique (6 lessons) is first choice

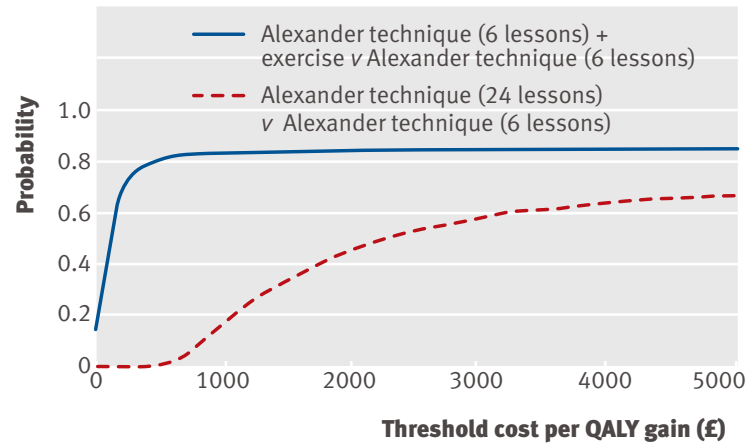

Second intervention when exercise is first choice

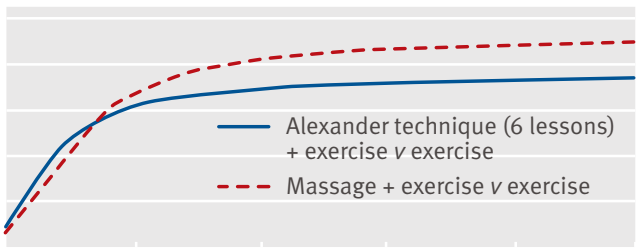

Third intervention

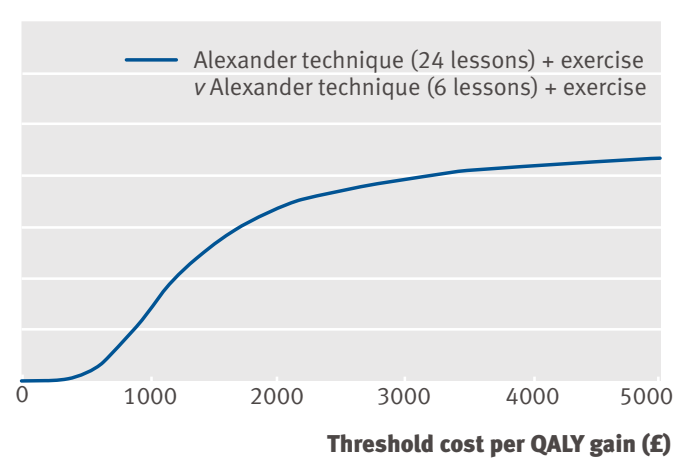

Fig 1 Cost effectiveness acceptability curves showing the probability that different interventions for persistent back pain are cost effective

who experienced a mean QALY reduction). Incremental cost effectiveness analysis suggests that, for a single therapy, exercise offered best value because of its low cost even though it did not provide the greatest benefit. For the two-stage therapies, exercise combined with six lessons in the Alexander technique performed well on all clinical outcomes and was relatively cost effective.

\section{Strengths and weaknesses of study}

This economic evaluation benefits from having been conducted alongside a rigorous randomised controlled trial. However, we faced two important methodological challenges, both of which indicate the need for further research. The first of these relates to missing data. Data on NHS resource use were collected from general practice records, so information on primary care consultations and prescribed drugs is likely to be of good quality. Some data on outpatient appointments could be missing, and the scale of this is unknown; it is, however, likely to be similar across the intervention groups and so should have a minimal effect on the incremental analysis. The quality of the questionnaire data was limited by the response rates, a factor that affected estimates of personal costs and QALYs, particularly for the participants allocated to normal care plus exercise. We had complete EQ-5D data (from all three time points) for 306 (53\%) participants and, as the missing values were unlikely to be randomly distributed, we were unable to rely on complete case analysis for realistic estimates as these could be affected by selection bias.

Missing data are a common problem in economic evaluation, ${ }^{19}$ as a large number of patient-level data are used, and a range of imputation techniques is available. Whichever method is used, the imputed data may still be unrepresentative of the true values, and the level and direction of any bias are unknown. We used an established statistical procedure to impute the missing values, which affected results particularly for patients receiving the exercise intervention. Our point estimates of QALY gain are similar to those found elsewhere in a similar patient group, ${ }^{3}$ though it is likely that the high level of missing EQ-5D data in our study $(38 \%)$ will produce added uncertainty (that is, more than indicated by the confidence intervals) around the QALY estimates. This uncertainty reinforces the importance of considering all outcomes when drawing conclusions about the relative cost effectiveness of each intervention.

The second methodological challenge relates to the design of the study. As it was a factorial design, we analysed and presented the clinical data in terms of the four factorial (marginal) groups. However, the interpretation of this analysis with respect to the economic evaluation is obscure. We have therefore presented an analysis of the eight individual group results as our main findings, thus preserving transparency and aiding interpretation. We also present results for the factorial groups, for completeness and synergy with the clinical results.

The cost of the interventions was a major factor in the total cost to the NHS. In our analysis we used the rate that teachers and therapists had been paid during the trial (£30 per session), which included payment for trial-related administration and inconvenience. Recent information suggests that an appropriate commercial rate in 2008 is in the range of $£ 18$ to $£ 45$ depending on 
Table $7 \mid$ Sensitivity analysis of uncertainty around the incremental cost effectiveness of interventions for persistent low back pain compared with most appropriate comparator groups. Values are incremental means $(95 \% \mathrm{Cl})$ unless stated otherwise

\begin{tabular}{|c|c|c|c|c|c|c|c|c|c|}
\hline & \multicolumn{9}{|c|}{ Intervention } \\
\hline & \multicolumn{4}{|c|}{ Without exercise } & \multicolumn{5}{|c|}{ With exercise } \\
\hline & Normal care & Massage & $\begin{array}{l}\text { Alexander } \\
\text { technique (6 } \\
\text { lessons) }\end{array}$ & $\begin{array}{c}\text { Alexander } \\
\text { technique ( } 24 \\
\text { lessons) }\end{array}$ & Normal care & Massage & Alexander techr & ique (6 lessons) & $\begin{array}{c}\text { Alexander } \\
\text { technique ( } 24 \\
\text { lessons) }\end{array}$ \\
\hline \multicolumn{10}{|l|}{$100 \%$ adherence } \\
\hline $\begin{array}{l}\text { Mean (SD) cost of } \\
\text { intervention ( }()\end{array}$ & $0(0)$ & $180(0)$ & $180(0)$ & $720(0)$ & $44(0)$ & $224(0)$ & \multicolumn{2}{|c|}{$224(0)$} & $764(0)$ \\
\hline $\begin{array}{l}\text { Mean (SD) total } \\
\text { NHS cost }(£)\end{array}$ & $54(100.4)$ & 278 (196) & $239(130)$ & 770 (141) & $168(523)$ & $303(360)$ & \multicolumn{2}{|c|}{$266(87)$} & $829(180)$ \\
\hline $\begin{array}{l}\text { Change from } \\
\text { baseline }\end{array}$ & 0 & 20 & 21 & 160 & 14 & 35 & \multicolumn{2}{|c|}{26} & 168 \\
\hline \multicolumn{10}{|c|}{ Excluding inpatient stays } \\
\hline $\begin{array}{l}\text { Mean (SD) total } \\
\text { NHS cost }(£)\end{array}$ & $54(100)$ & $258(204)$ & 218 (146) & $610(262)$ & 84 (145) & $237(140)$ & \multicolumn{2}{|c|}{$240(107)$} & $661(328)$ \\
\hline $\begin{array}{l}\text { Change from } \\
\text { baseline }\end{array}$ & 0 & 0 & 0 & 0 & -70 & -30 & \multicolumn{2}{|c|}{0} & 0 \\
\hline \multicolumn{10}{|c|}{ Complete case analysis } \\
\hline $\begin{array}{l}\text { Mean (SD) } \\
\text { personal costs }(£) \\
(n=358)\end{array}$ & $292(457)$ & 579 (1561) & 361 (1151) & 273 (459) & $54(64)$ & $287(431)$ & \multicolumn{2}{|c|}{$265(503)$} & 507 (1307) \\
\hline $\begin{array}{l}\text { Change from } \\
\text { baseline }\end{array}$ & -83 & 152 & 87 & -8 & -133 & -70 & \multicolumn{2}{|c|}{66} & 60 \\
\hline \multicolumn{10}{|l|}{ QALY gain } \\
\hline $\begin{array}{l}\text { Incremental QALY } \\
\text { gain }(95 \% \mathrm{Cl}) \\
(\mathrm{n}=306)\end{array}$ & - & $\begin{array}{c}-0.02(-0.08 \text { to } \\
0.05)^{\star}\end{array}$ & $\begin{array}{c}-0.01(-0.06 \text { to } \\
0.05)^{\star}\end{array}$ & $\begin{array}{c}0.04(-0.01 \text { to } \\
0.09) \dagger\end{array}$ & $\begin{array}{c}-0.03(-0.08 \text { to } \\
0.03)^{\star}\end{array}$ & $\begin{array}{c}0.06(0.00 \text { to } \\
0.12) \ddagger\end{array}$ & $\begin{array}{c}0.04(-0.03 \text { to } \\
0.11) \ddagger\end{array}$ & $\begin{array}{c}0.02(-0.04 \text { to } \\
0.08) \dagger\end{array}$ & $\begin{array}{c}0.05(-0.01 \text { to } \\
0.11) \S\end{array}$ \\
\hline $\begin{array}{l}\text { Change from } \\
\text { baseline }\end{array}$ & - & 0.01 & 0.03 & -0.02 & 0.06 & -0.04 & -0.02 & 0.00 & -0.02 \\
\hline
\end{tabular}

${ }^{\star}$ Compared with normal care alone.

†Compared with Alexander technique (6 lessons) alone.

$\ddagger$ Compared with normal care plus exercise.

$\S$ Compared with Alexander technique (6 lessons) plus exercise.

experience, location, overheads, running expenses, and local competition. These factors limit the generalisability of our results, though, as our payment was at the upper end of this range, our results will be conservative and the conclusions remain valid.

We did not include the cost of lost productivity in our comparative analysis as the data were incomplete and there was no evidence of a difference across groups. However, back pain clearly has a considerable cost to society. Maniadakis estimated UK production losses to be in the region of $£ 3440 \mathrm{~m}(1998) .{ }^{1}$ Our estimate of just under a week lost per annum per patient with prevalent back pain is slightly less than that of Maniadakis. After adjusting for population changes and inflation, our (conservative) estimate would imply annual losses in excess of $£ 3000 \mathrm{~m}$.

The results of this evaluation are limited by the time horizon of the trial. A longer follow-up would have been ideal but was impractical, and there are no reliable data in the literature to populate a model. Nevertheless, it is reasonable to speculate that benefits of lessons in the Alexander technique could have a more lasting effect than either massage or a prescription for exercise. The teaching method used in the Alexander technique lessons ${ }^{5}$ equips patients with life skills they are more likely to be able to use beyond the intervention period.

\section{Meaning of the study}

This study suggests that at $£ 20000$ per QALY there is more than an $85 \%$ chance that a general practitioner's exercise prescription with a nurse follow-up, or a short series of lessons in the Alexander technique, will be cost effective for patients with chronic or recurrent nonspecific back pain.

It is important for clinicians and policy makers to consider a range of outcomes when drawing conclusions about the cost effectiveness of the interventions. ${ }^{20}$ In this study we compared the costs of interventions with two distinct types of outcome. Firstly, we compared cost with estimated QALY gain, based on responses to questions gathered on three occasions about health related quality of life. These questions are broad in nature, and, because we used the "area under the curve" method of analysis, the estimates of QALY gain incorporated the information gathered at interim and end time points. Secondly, we compared cost per patient with clinical outcomes at 12 months, which evaluated patients' ability to perform daily activities and their days in pain during the previous four weeks.

Our associated clinical paper ${ }^{5}$ showed that an exercise prescription alone had only a moderate effect on disability scores and that massage was unlikely to provide a sustained improvement, whereas lessons in 


\section{WHAT IS ALREADY KNOWN ON THE SUBJECT}

Back pain is one of the most common and costly reasons for patients to consult in primary care

A class based exercise programme with spinal manipulation has been shown to offer good value in the treatment of back pain

The costs and benefits of massage and lessons in the Alexander technique have not been assessed

\section{WHAT THIS STUDY ADDS}

Massage, lessons in the Alexander technique, and an exercise prescription all provided benefits to patients over a 12 month period

A series of six lessons in the Alexander technique combined with an exercise prescription was the most effective and cost effective option for the NHS pain: clinical outcomes, costs, and preferences. $B M$ 1999;319:279-83.

3 UK BEAM Trial Team. United Kingdom back pain exercise and manipulation (UK BEAM) randomised trial: cost-effectiveness of physical treatments for back pain in primary care. $B M$ 2004;329:1381.

4 Ratcliffe J, Thomas KJ, MacPherson H, Brazier J. A randomised controlled trial of acupuncture care for persistent low back pain: costeffectiveness analysis. BMJ 2006;333:626.

5 Little P, Lewith G, Webley F, Evans M, Beattie A, Middleton K, et al. Randomised controlled trial of Alexander technique lessons, exercise, and massage (ATEAM) for chronic and recurrent back pain. BMJ 2008;337:a884.

6 Fox Z, Nitsch D, Wang D, Bakhai A. Factorial design. In: Wang D, Bakhai A, eds. Clinical trials: a practical guide to design, analysis, and reporting. London: Remedica, 2006.

7 Beurskens AJ, de Vet HC, Koke AJ. Responsiveness of functional status in low back pain: a comparison of different instruments. Pain 1996;65:71-6.

8 Von Korff M, Ormel J, Keefe FJ, Dworkin SF. Grading the severity of chronic pain. Pain 1992;50:133-49.

9 EuroQol Group. EuroQol-a new facility for the measurement of health-related quality of life. Health Policy 1990;16:199-208

term over a range of outcomes. Considering the level of uncertainty around the effectiveness of normal care plus exercise, and taking account of all evidence, we conclude that a series of six lessons in Alexander technique combined with an exercise prescription seems the most effective and cost effective option for the treatment of back pain in primary care.

Contributors: Jackie Brown designed the economic evaluation and Alan Montgomery and Tim Peters gave statistical advice. PL and GL had the original idea for the study, and DS and FO had been working on a paralle protocol; the protocol was developed by all the authors. PL and DS were the principal investigators, and FW coordinated the trial on a day-to-day basis. KM, JB, and AB managed the data. The analysis was carried out by $\mathrm{SH}$, with all authors contributing to the interpretation of the results. $\mathrm{SH}$ wrote the paper, with comments and contributions from all authors, who all approved the final version. SH is guarantor for the paper Funding: The study was funded by the Medical Research Council (ISRCTN 26416991 (2000-2005)). All researchers are independent of the funding body.

Competing interests: None declared.

Ethical approval: The Southwest Multicentre Research Ethics Committee (2000 MREC: 01/06/54).

Provenance and peer review: Not commissioned; externally peer reviewed.

1 Maniadakis N, Gray A. The economic burden of back pain in the UK. Pain 2000;84:95-103.

2 Moffett JK, Torgerson D, Bell-Syer S, Jackson D, Llewlyn-Philips H, Farrin A, et al. Randomised controlled trial of exercise for low back
10 Curtis L, Netten A. Unit costs of health and social care 2005. PSSRU University of Kent, 2005.

11 Department of Health. National tariff 2005-06. www.dh.gov.uk/en/ Publicationsandstatistics/Publications/ PublicationsPolicyAndGuidance/DH 4091529.

12 British Medical Association, Royal Pharmaceutical Society of Great Britain. British national formulary. London: BMA, RPS 2005. (No 50.) www.bnf.org/bnf.

13 Automobile Association. Motoring costs: running cost tables. www. theaa.com/motoring advice/running costs/index.html.

14 Beale N, Hollinghurst S, Taylor G, Gwynne M, Peart C, Straker-Cook D. The costs of care in general practice: patients compared by the council tax valuation band of their home address. Fam Pract 2005;22:317-22.

15 StataCorp. Stata statistical software: Release 9. College Station, TX: StataCorp, 2005.

16 Dolan P, Gudex C, Kind P, Williams A. A social tarifffor EuroQol: results from a UK general population survey. Centre for Health Economics, University of York, 1995

17 Manca A, Hawkins N, Sculpher M. Estimating mean QALYs in trialbased cost-effectiveness analysis: the importance of controlling for baseline utility. Health Econ 2005;14:487-96.

18 Brouwer WB, Koopmanschap MA, Rutten FF. Productivity costs measurement through quality of life? A response to the recommendation of the Washington Panel. Health Economics

19 Briggs A, Clark T, Wolstenholme J, Clarke P. Missing ... presumed at random: cost-analysis of incomplete data. Health Economics 2003;12:377-92.

20 Coast J. Is economic evaluation in touch with society's health values? BMJ 2004;329:1233-6.

Accepted: 5 October 2008 1997;6:253-9. 